\title{
PENGOLAHAN DAN PENYAJIAN MAKANAN NEGARA INDIA
}

\author{
Wisnu Edi Saputra \\ Jerry Haris \\ Muhammad Al Ghifari \\ Program Studi Pendidikan Kesejahteraan Keluarga \\ Fakultas Pariwisata Dan Perhotelan \\ Universitas Negeri Padang \\ Email : wisnu.edi.saputra@gmail.com \\ Jerryharis42@gmail.com \\ Muhammad.al.ghifari@gmail.com
}

\begin{abstract}
Abstrak
Republik India (bahasa Hindi: भारत गणराज्य; Bhārat Gaṇarājya) adalah sebuah negara di Asia yang memiliki jumlah penduduk terbanyak kedua di dunia, dengan populasi lebih dari satu miliar jiwa, dan adalah negara terbesar ketujuh berdasarkan ukuran wilayah geografis. Jumlah penduduk India tumbuh pesat sejak pertengahan 1980-an. Ekonomi India adalah terbesar keempat di dunia dalam PDB, diukur dari segi paritas daya beli (PPP), dan salah satu pertumbuhan ekonomi tercepat di dunia. India, negara dengan sistem demokrasi liberal terbesar di dunia, juga telah muncul sebagai kekuatan regional yang penting, memiliki kekuatan militer terbesar, dan memiliki kemampuan senjata nuklir.

Terletak di Asia Selatan dengan garis pantai sepanjang $7.000 \mathrm{~km}$, dan bagian dari anak benua India, India merupakan bagian dari rute perdagangan penting, dan bersejarah. Dia membagi perbatasan dengan Pakistan, Republik Rakyat Tiongkok, Myanmar. Bangladesh, Nepal, Bhutan, dan Afganistan. Sri Lanka, Maladewa, dan Indonesia adalah negara kepulauan yang bersebelahan.

India adalah letak dari peradaban kuno seperti Peradaban Lembah Sungai Indus dan merupakan tempat kelahiran dari empat agama utama dunia: Hindu, Buddha, Jainisme, dan Sikhisme. Negara ini merupakan bagian dari Britania Raya sebelum meraih kemerdekaan pada 1947. Republik India (bahasa Hindi: भारत गणराज्य; Bhārat Gaṇarājya) adalah sebuah negara di Asia yang memiliki jumlah penduduk terbanyak kedua di dunia, dengan populasi lebih dari satu miliar jiwa, dan adalah negara terbesar ketujuh berdasarkan ukuran wilayah geografis. Jumlah penduduk India tumbuh pesat sejak pertengahan 1980-an. Ekonomi India adalah terbesar keempat di dunia dalam PDB, diukur dari segi paritas daya beli (PPP), dan salah satu pertumbuhan ekonomi tercepat di dunia. India, negara dengan sistem demokrasi liberal terbesar
\end{abstract}


di dunia, juga telah muncul sebagai kekuatan regional yang penting, memiliki kekuatan militer terbesar, dan memiliki kemampuan senjata nuklir.

Terletak di Asia Selatan dengan garis pantai sepanjang 7.000 km, dan bagian dari anak benua India, India merupakan bagian dari rute perdagangan penting, dan bersejarah. Dia membagi perbatasan dengan Pakistan, Republik Rakyat Tiongkok, Myanmar. Bangladesh, Nepal, Bhutan, dan Afganistan. Sri Lanka, Maladewa, dan Indonesia adalah negara kepulauan yang bersebelahan.

India adalah letak dari peradaban kuno seperti Peradaban Lembah Sungai Indus dan merupakan tempat kelahiran dari empat agama utama dunia: Hindu, Buddha, Jainisme, dan Sikhisme. Negara ini merupakan bagian dari Britania Raya sebelum meraih kemerdekaan pada 1947. . Adapun hidangan khas masyarakat India yaitu biryani

Kata kunci: Pengolahan Makanan India, Penyajian Makanan India, Makanan Khas India. 


\section{Pendahuluan}

Republik India (bahasa Hindi: भारत गणराज्य; Bhārat Gaṇarājya) adalah sebuah negara di Asia yang memiliki jumlah penduduk terbanyak kedua di dunia, dengan populasi lebih dari satu miliar jiwa, dan adalah negara terbesar ketujuh berdasarkan ukuran wilayah geografis. Jumlah penduduk India tumbuh pesat sejak pertengahan 1980-an. Ekonomi India adalah terbesar keempat di dunia dalam PDB, diukur dari segi paritas daya beli (PPP), dan salah satu pertumbuhan ekonomi tercepat di dunia. India, negara dengan sistem demokrasi liberal terbesar di dunia, juga telah muncul sebagai kekuatan regional yang penting, memiliki kekuatan militer terbesar, dan memiliki kemampuan senjata nuklir.

Terletak di Asia Selatan dengan garis pantai sepanjang $7.000 \mathrm{~km}$, dan bagian dari anak benua India, India merupakan bagian dari rute perdagangan penting, dan bersejarah. Dia membagi perbatasan dengan Pakistan, Republik Rakyat Tiongkok, Myanmar. Bangladesh, Nepal, Bhutan, dan Afganistan. Sri Lanka, Maladewa, dan Indonesia adalah negara kepulauan yang bersebelahan.

India adalah letak dari peradaban kuno seperti Peradaban Lembah Sungai Indus dan merupakan tempat kelahiran dari empat agama utama dunia: Hindu, Buddha, Jainisme, dan Sikhisme. Negara ini merupakan bagian dari Britania Raya sebelum meraih kemerdekaan pada 1947.

Seluruh negara-negara bagian India di utara, dan timur laut dibentuk oleh Banjaran Himalaya. Wilayah lainnya terdiri dari hamparan Indo-Gangetik yang subur. Di sebelah barat yang berbataskan Pakistan tenggara terdapat Gurun Thar. Semenanjung India di selatan hampir seluruhnya merupakan bagian dari hamparan Dekan (Deccan). Di kedua sisi hamparan ini terdapat dua banjaran pesisir yang berbukit-bukit, Ghats Barat, dan Ghats Timur.

India memiliki beberapa sungai besar seperti Sungai Gangga, Brahmaputra, Yamuna, Godavari, dan Krishna. Sungai-sungai tersebutlah yang menyebabkan suburnya hamparanhamparan di sebelah utara India sehingga cocok untuk ditanam.

Cuaca India beragam, dari cuaca tropis di selatan hingga ke cuaca menengah di utara. Sebagian dari India yang terletak di pegunungan Himalaya memiliki cuaca tundra. India memperolehi hujannya dari monsun.

Di India, makanan dimakan sambil duduk di kursi, di lantai, di kursi rendah, atau di atas bantal untuk duduk. Secara tradisional, makanan dimakan langsung dengan tangan, biasanya dengan jari-jari dan telapak tangan kanan, tanpa sendok dan garpu. Sewaktu makan dengan tangan, suhu makanan bisa dirasakan dengan tangan sebelum disuap ke mulut. Mulut juga bisa dicegah dari melepuh akibat makanan panas.Set menu thali terdiri dari beraneka masakan daerah di India dalam mangkuk-mangkuk kecil yang disajikan dalam piring logam berukuran besar. Hidangan ini dilengkapi dengan raita dan beraneka jenis roti-rotian seperti naan, puri, roti, atau nasi.

Alat makan seperti sendok dan garpu dipakai oleh kalangan atas di India. Sendok dan garpu merupakan pengaruh budaya Romawi pada abad ke-16, dan mulanya hanya dikenal kalangan atas di India Utara. Perdagangan lada dengan orang Romawi menyebabkan dikenalnya 
alat-alat makan di Asia. Hidangan yang mengandung nasi biasanya boleh dimakan dengan sendok dan garpu, namun memakan roti dengan pisau atau garpu dianggap tidak sopan.

\section{Metodologi penelitian}

Jenis penelitian ini adalah kualitatif.fokus penelitian adalah makanan khas dan cara penyajian dan tata cara makan orang India. Teknik dalam mengumpulkan data dikumpulkan dengan mengkaji dengan sumber literatur.

\section{Pembahasan}

\section{Tata cara penyajian makanan Malaysia}

Dalam konfigurasi tradisional India berikut diamati. Biasanya piring dilayani oleh sejumlah kecil semua item makanan Kemudian tuan rumah mengucapkannya mantra kebaktian. Kemudian tuan rumah meminta tamu untuk memulai makanan. Makanan dimulai setelah 'chitrahuti' (menempatkan sejumlah kecil makanan di luar piring) dan seteguk air di tangan yang disebut 'Achaman'. Makanan ini biasanya disajikan oleh wanita. Tuan rumah meminta semua orang untuk mengambil makanan perlahan-lahan. Tuan rumah meminta tamu untuk mengambil jumlah lebih banyak makanan manis yang disebut 'Pakwann'. Ritual ini disebut 'Agraha'. Tidak melakukan 'Agraha' diasumsikan kekasaran. Semua orang meninggalkan tempat setelah semua selesai. A 'Paan, sauf atau Supari' yang ditawarkan oleh tuan rumah setelah makan.

Aturan kardinal makan adalah dengan menggunakan tangan kanan saat makan atau menerima makanan. Cuci Tangan, baik sebelum duduk di meja dan setelah makan, adalah penting. Membersihkan dengan kain atau tisu kertas dapat dianggap tidak higienis.

Sejumlah kecil makanan yang diambil, memastikan makanan yang tidak mencapai telapak tangan. Hal ini dianggap penting untuk menyelesaikan setiap item di piring untuk menghormati makanan yang disajikan. Secara tradisional, makanan harus dimakan seperti dilayani, tanpa meminta garam atau merica. Hal ini, namun, sekarang diterima untuk meminta garam atau merica dengan menyebutkan bahwa Anda ingin lebih dari itu.

Distorsi atau bermain dengan makanan tidak dapat diterima. Makan pada kecepatan menengah ini penting, karena makan terlalu lambat mungkin menyiratkan ketidaksukaan makanan dan makan terlalu cepat kasar. Umumnya itu tidak bisa diterima untuk bersendawa, slurp, atau meludah. Menatap piring lain diner ini diambil sebagai kasar. Hal ini tidak tepat untuk membuat suara saat mengunyah. Beberapa item makanan India dapat membuat suara, sehingga sangat penting untuk menutup mulut dan mengunyah pada kecepatan menengah.

Di meja makan, perhatian harus diberikan pada perilaku tertentu yang mengindikasikan gangguan atau kekasaran. Menjawab panggilan telepon, mengirim pesan, dan menggunakan bahasa yang tidak pantas dianggap tidak pantas saat makan dan sementara orang tua yang hadir.

\section{Alat memasak yang sering digunakan dalam masakan india}

a. Charni, pengayak terigu agar roti naan halus dan lembut

Kalau hobi nonton acara kompetisi masak di televisi, kamu akan tahu bahwa peserta berdarah India senang sekali membuat flatbread dari nol. Untuk memastikan adonan roti tidak menggumpal, mereka menggunakan charni atau 
sejenisnya untuk mengayak terigu. Charni memiliki penyaring yang lubangnya halus. Jika dialasi dengan kain kasa yang halus, kamu bisa menggunakan alat ini untuk menyaring yogurt sebagai saus pendamping kari.

b. Belan, serupa rolling pin untuk meratakan adonan roti

Agar flatbread bisa tipis, orang India menggunakan belan untuk menggiling adonan sampai mendapatkan tingkat ketebalan yang diinginkan. Fungsinya sama dengan rolling pin versi Amerika yang cenderung besar dan bulat. Bedanya, belan lebih langsing dengan pegangan yang kecil dan ringan. Tak hanya untuk membuat flatbread, kamu bisa memanfaatkannya untuk membuat kulit pizza atau pie.

c. Patli, kayu bulat untuk alas menggiling flatbread

Belan dan patli seperti cobek dan ulekan, yang nyaris tak terpisahkan. Patli terbuat dari kayu besar yang rata, sehingga bisa menggiling adonan dengan sempurna. Sekilas seperti talenan kayu, tapi jauh lebih tebal. Bentuknya bulat, karena rata-rata flatbread ala India berbentuk bulat, seperti naan, chapatti, dan puri. Kamu juga bisa memakainya untuk menggiling adonan roti atau sebagai piring saji, misalnya untuk menyuguhkan samosa.

d. Kadai, wajan datar dari besi cor untuk menggoreng makanan

Di dapur-dapur India kamu akan menemukan kadai dari besi cor, meski kini hadir pula versi lebih modern dengan bahan dari stainless steel dan lapisan antilengket. Tidak seperti wajan yang melengkung, kadai memiliki dasar yang rata dan pinggiran yang hampir tegak lurus. Kamu bisa menggoreng apa pun di wajan tersebut dengan minyak banyak, seperti mendoan dan pisang goreng.

e. Jhaara, penyaring minyak sekaligus untuk membalik makanan

Jika kamu biasanya membalik gorengan dengan sutil, orang India kerap melakukannya dengan jhaara. Tampilannya seperti spatula dari bahan logam, berbentuk bulat dan berukuran agak besar, dengan lubang-lubang kecil di seluruh spatula. Kamu bisa menggunakan alat ini untuk mengambil sayuran yang direbus di panci, atau untuk mengeringkan gorengan dari minyak agar tidak berminyak ketika disajikan.

f. Chimta, penjepit besi untuk membalik flatbread

Umumnya terbuat dari besi, chimta digunakan untuk membalik flatbread ketika sedang dimasak. Ujungnya yang lancip, bisa juga digunakan untuk menjepit makanan lain yang tipis atau kecil, atau membalik kerupuk yang sedang digoreng. Chimta versi masa kini bisa ditemukan dari bahan stainless steel yang mudah dibersihkan.

g. Masala dabba, wadah untuk menyimpan berbagai jenis rempah

Kamu pasti sudah tahu bahwa masakan India menggunakan banyak sekali rempah. Agar tak berserakan di mana-mana dan sulit dicari, mereka menggunakan masala dabba untuk menyimpan rempah yang kerap digunakan. Terbuat dari stainless steel, masala dabba terdiri dari beberapa wadah dan sendok kecil, sehingga memudahkan ketika memasak.

\section{Bumbu dan rempah yang sering digunakan dalam masakan india}

Bumbu dan rempah yang sering digunakan dalam masakan india yaitu: kapulaga, cengkih, kulit cassia, merica hitam, jinten, fenugreek, pala, biji mustard, dan kunyit. 


\section{Makanan khas india}

Ada beberapa makana khas India yang sudah dikenal luas di dunia. Makanan khas India sudah di terima global. Jadi enggak susah menemukan makanan India di beberapa negara. Biasanya restoran-restoran India di luar negeri menyediakan menu khas India. Menu khas India antara lain : Biryani, butter chicken, idli, gulab jamun, kathi roll, papri chaat, pani puri, jalebi, chicken tandoori, dosa, samosa, naan, tikka masala, vada, laddu, papaddum, kofta, lassi, dhokla, chai tea, chloe bhature, gajar halwa, raita, dan kulfi.

\section{Simpulan dan saran}

\section{Simpulan}

Imigrasi dan percampuran budaya secara terus menerus berlangsung di India selama ribuan tahun. Iklim India yang berbeda-beda menurut daerahnya, mulai dari daerah beriklim tropis hingga daerah beriklim Pegunungan Alpen, dan menyediakan beraneka ragam bahan makanan. Bagi sebagian orang India, makanan sudah menjadi simbol keagamaan dan identitas sosial dengan beraneka ragam tabu dan pelarangan. Sebagian penganut Jainisme, misalnya, tidak makan akar-akaran atau makanan yang diambil dari dalam tanah. Sebagian penganut Hindu dan Buddha adalah juga vegetarian. Antara $20 \%$ hingga $42 \%$ penduduk India adalah vegetarian ketat, sementara hanya $30 \%$ dari penduduk India yang pemakan daging.

\section{Saran}

Menyadari bahwa penulis masih jauh dari kata sempurna, kedepannya penulis akan lebih fokus dan details dalam menjelaskan tentang makalah di atas dengan sumber sumber yang lebih banyak yang tentunya dapat di pertanggung jawabkan. Untuk saran bisa berisi kritik atau saran terhadap penulisan juga bisa untuk menanggapi terhadap kesimpulan dari bahasan makalah yang telah di jelaskan. Untuk bagian terakhir dari makalah adalah daftar pustaka. Pada kesempatan lain akan saya jelaskan tentang daftar pustaka makalah.

\section{Daftar pustaka}

https://id.wikipedia.org/wiki/India

https://www.shopback.co.id/blog/25-makanan-khas-india-yang-terkenal-di-dunia

http://desainbloghebat.blogspot.com/2014/08/tata-cara-makan-di-india-table-manner.html

https://review.bukalapak.com/food/ini-nama-dan-manfaat-7-alat-masak-khas-india-yang-bisakamu-pakai-di-dapur-77911

https://kumparan.com/@kumparanfood/9-jenis-rempah-yang-biasa-digunakan-dalam-masakanindia

Zulfikar.D.(2019).Pengolahandanpenyajianmakananmalaysia-OSF.IO/INA-RXIV

Zulfikar,D.(2019).Pengolahandanpenyajianmakanannegarathailand-OSF.IO/INA-RXIV 